\title{
Errázuriz, T. y Greene, R. (2017). Salcedo. Talca: Editorial Bifurcaciones.
}

Nélida Ramírez Naranjo*

El texto es una producción colectiva y ad honorem, llevada a cabo por muchos autores que, por distintas circunstancias, conocieron y estimaron a Rodrigo Salcedo (1969-2016), sociólogo de la Pontificia Universidad Católica de Chile, magíster y doctor en Ciencia Política de la Universidad de Illinois, en Chicago. El año 2002 regresó a Chile y se incorporó a la escuela de Sociología de la Universidad Alberto Hurtado, luego se integró al Instituto de Estudios Urbanos y Territoriales de la Pontificia Universidad Católica de Chile. En 2011 se trasladó a la Universidad Católica del Maule, donde fundó la primera escuela de sociología entre Santiago y Concepción, fue decano de la facultad de Ciencias Sociales y Económicas (FACSE) y creó el Centro de Estudios Territoriales (CEUT). En su carrera académica participó y lideró proyectos de investigación FONDECYT, Anillos y Milenio, publicó profusamente y participó en comités editoriales en destacadas revistas de estudios urbanos.

Conocí a Rodrigo en julio de 2012, en una entrevista de trabajo cuando postulaba a un cargo de académica en la Escuela de Trabajo Social, vía concurso público. Me llamó mucho la atención la agudeza de sus preguntas, su consideración por mis conocimientos, experiencia profesional y académica, y por mi situación familiar, dado que, de ser seleccionada, debía trasladarme a vivir en Curicó. Finalmente fui aceptada; han transcurrido 7 años y en agradecimiento a él y reconociendo su destacada trayectoria, me atrevo a compartir con ustedes la reseña de su libro.

Chilena, PhD. Académica Departamento de Ciencias Sociales Escuela de Trabajo Social Universidad Católica del Maule. E-mail: nramirez@ucm.cl 
El texto recorre temas relativos a la Teoría del Espacio, Identidad de Clase, Vivienda Social, Barrio Cerrado, Malls y su pensamiento político. Asimismo, considera la prolífica y destacada obra de Salcedo como analista e intelectual, la cual ha sido diseminada en múltiples artículos, capítulos de libros, estudios, informes, prólogos, entrevistas y columnas de actualidad. Dada la relevancia de sus trabajos, se han difundido en diferentes medios e idiomas.

El propósito del libro es dar a conocer la fuerza de su contribución al campo de los estudios urbanos y políticos, y busca convertirse en un referente obligado para entender la ciudad contemporánea como una inacabable construcción social, política y cultural.

Luego de la presentación del libro, aparecen tres apartados previos que aluden a la figura de Rodrigo: i. Rodrigo Salcedo en la comunidad de académicos urbanos; ii. Rodrigo Salcedo y la escuela de Urbanismo de Los Angéles, y iii. Rodrigo Salcedo, lecciones de un optimista.

A continuación se presenta una breve reseña del primer capítulo "Teoría del Espacio". Consciente de los peligros que supone el traspaso de teorías foráneas o la validación social de los falsos supuestos, los artículos de esta sección permiten deconstruir y rearticular algunas de las principales teorías sobre el espacio que dominan el campo de los estudios urbanos. Desde una mirada escéptica y crítica, fundada en el conocimiento empírico de las ciudades, Salcedo invita a repensar problemas tan diversos como el modelo de desarrollo urbano, la noción del espacio público o la naturaleza del gueto.

El segundo capítulo, "Identidad de Clase", recuerda que toda estratificación socioeconómica es un ejercicio de abstracción y generalización que tiene, en la mayoría de los casos, una justificación práctica. La realidad social se presenta siempre más dinámica y compleja, los límites son difusos y los grupos objetivos susceptibles de cualquier clasificación. Basado en un amplio estudio etnográfico, el autor plantea la necesidad de superar la taxonomía basada en divisiones arbitrarias y poco representativas, a lo cual se une una reflexión mayor sobre problemas como identidad de clase, los símbolos de estatus, las estrategias de distinción y la movilidad social, entre otros.

El tercer capítulo, "Vivienda Social", presenta reflexiones y análisis que son resultado de la participación de Salcedo en diversos núcleos 
de investigación, abordando preguntas que invitan a reflexionar sobre las consecuencias directas e indirectas de la política habitacional chilena en las últimas décadas. ¿Cuál es el real impacto de las políticas habitacionales chilenas en las condiciones de vida de los pobres urbanos? ¿Qué importancia tienen la localización de los proyectos y la mixtura social del área en que se construyen? ¿Cómo se reproduce la lógica de segregación al interior de los barrios populares estigmatizados? ¿Cómo afecta a la cohesión social y a la viabilidad de consolidar un proyecto colectivo? ¿Qué estrategias desarrollan los habitantes para contrarrestar fenómenos como la estigmatización, la inseguridad y el deterioro de sus barrios?

El cuarto capítulo, "Barrio Cerrado", incluye una mirada crítica acerca de los suburbios y barrios cerrados, tema dominante en los estudios urbanos y articulado principalmente desde la escuela de Los Ángeles. Basado en su experiencia, Salcedo investiga en barrios y áreas de Santiago donde se han instalado proyectos inmobiliarios privatizados y enrejados. El autor plantea alternativas y posibilidades de integración, considerando el barrio enrejado como frontera y no como barrera, lo cual tendría relación con aspectos como escalas de segregación y ciertas condiciones propias de la identidad y la cultura nacional.

El quinto capítulo, “Mall”, invita a dejar de lado los compromisos ideológicos y el referente norteamericano de este espacio, para descubrir en terreno las particularidades que distinguen a estos recintos en el caso chileno. El trabajo etnográfico del autor permite debatir y hasta derribar los supuestos en los que se sustenta esta aparente marginalidad de los malls, proponiendo en cambio un certero diagnóstico al respecto. Salcedo refiere que el éxito de los malls se explicaría, entre otras cosas, por proveer un espacio público de calidad allí donde el Estado y actores del sector privado han fallado, y de ofrecer experiencias sobre las que distintos sujetos construyen y negocian sus identidades.

Finalmente, "Pensamiento Político" desmenuza con enorme destreza y conocimiento las dinámicas intra e interpartidistas que han caracterizado a la centroizquierda nacional desde el retorno a la democracia. El resultado es la identificación de un conjunto de lógicas y patrones ampliamente compartidos, pero que habitualmente no son considerados y que tienen un origen pragmático. A partir de este co- 
nocimiento, el autor ensaya nuevas explicaciones para entender la trayectoria y proyecciones de la política partidista chilena.

Invito a los interesados a revisar con atención las agudas y consistentes propuestas de Rodrigo Salcedo, vigentes, provocadoras e innovadoras. 